\title{
Simulation of Opening Angle of Archimedes Wind Turbine Design Based on the Fibonacci Series
}

\author{
Eva Hertnacahyani Herraprastanti*, Widianto Agung Saputro \\ Department of Mechanical Engineering, Sekolah Tinggi Teknologi Ronggolawe, Cepu, Indonesia \\ *Corresponding author E-mail: ev.hertna@gmail.com
}

Manuscript received 30 Oct 2021; revised 10 Nov 2021; accepted 1 Jan 2022. Date of publication 10 Jan 2022

\begin{abstract}
The configuration of new type of turbine is the Archimedes wind turbine with a spiral structure whose design is inspired by logarithmic spirals. This type of wind turbine uses lift and drag to harness the kinetic energy of the wind. The eccentric design has aerodynamic characteristics that have been the focus of previous research. The design is made from the arrangement of the Fibonacci sequence $(1 \times 1,2 \times 2,3 \times 3,5 \times 5,8 \times 8)$ or commonly known as the golden ratio. This study aims to analyze the coefficient of lift $\left(\mathrm{C}_{\mathrm{L}}\right)$ and coefficient of drag $\left(\mathrm{C}_{\mathrm{D}}\right)$ with variations opening angle of $35^{\circ}, 45^{\circ}, 65^{\circ}$, air fluid, turbulent flow, Re 1200, pressure distribution $1 \mathrm{~atm}$, wind speed 5,5 and $15 \mathrm{~m} / \mathrm{s}$. The results is at wind speed of $5.5 \mathrm{~m} / \mathrm{s}$, an angle of $35^{\circ}$, the $C_{L}$ value is $1.07 \mathrm{E}+02$, the $C_{D}$ value is $4.02 \mathrm{E}+04$. At wind speed of $5.5 \mathrm{~m} / \mathrm{s}$, an angle of $45^{\circ}$, the $C_{L}$ value is $1.08 \mathrm{E}+04$, the $C_{D}$ value is $1.77 \mathrm{E}+01$. At wind speed of $5.5 \mathrm{~m} / \mathrm{s}$, an angle of $65^{\circ}$, the $\mathrm{C}_{\mathrm{L}}$ value is $1.84 \mathrm{E}+06$, the $\mathrm{C}_{\mathrm{D}}$ value is $3.68 \mathrm{E}+04$. At wind speed of $15 \mathrm{~m} / \mathrm{s}$, an angle of $35^{\circ}$, the $\mathrm{C}_{\mathrm{L}}$ value is $2.20 \mathrm{E}+03$, the $C_{D}$ value is $9.76 \mathrm{E}+02$. At wind speed of $15 \mathrm{~m} / \mathrm{s}$, an angle of $45^{\circ}$, the $C_{L}$ value is $5.51 \mathrm{E}+04$, the $C_{D}$ value is $4.12 \mathrm{E}+02$. At wind speed of $15 \mathrm{~m} / \mathrm{s}$, an angle of $65^{\circ}$, the $C_{L}$ value is $5.96 \mathrm{E}+01$, the $C_{D}$ value is $1.33 \mathrm{E}+03$. Based on this, it can be concluded that at wind speed of $5.5 \mathrm{~m} / \mathrm{s}$ the higher the opening angle, the higher $\mathrm{C}_{\mathrm{L}}$ produced. At wind speed of $15 \mathrm{~m} / \mathrm{s}$ the larger the opening angle the $\mathrm{C}_{\mathrm{D}}$ increases. This is because the higher the angle, the more it receives sweeps or catches the wind. While the unstable value generated in this simulation is generally a weakness in the wind turbine design.
\end{abstract}

Keywords: Archimedes Wind Turbine, Opening Angle Lift, Drag, Fibonacci.

\section{Introduction}

The mathematician Archimedes applied the spiral curve to (Fibonacci Spiral) formake blade designs with estimates of the spiral [1]. From the design of these blades can create a new configuration of turbine blades adopted in a spiral turbine which is considered a third type of wind turbine, namely Archimedes Wind Turbine (ASWT). ASWT is a spiral structure turbine that uses the principle of Achimedes [2]. In general, without realizing it, the flow of fluids in the form of gases and liquids is often encountered in everyday life, such as when airplanes fly in the air, cars or motorcycles go fast or slow, fish swim and when humans run. It is certain that there will be an obstacle in the form of a lift or drag force. The magnitude of the lift force acting on an object flowing with a fluid is generally called the lift coefficient $\left(\mathrm{C}_{\mathrm{L}}\right)$. In addition to the coefficient of lift $C_{L}$ there is a drag coefficient $C_{D}$ which shows how much an object can pass through fluid resistance. This event can be said to be a submerged object flow. Because in this situation the objects are completely surrounded by fluids and the flow is called external flow or external flow and sometimes external flow involving air fluids is often called aerodynamics [3]. Solidworks is a CAD (Computer Aided Design) software published by Dassault Systemes. This software is used to build the geometry of the manufacturing model. In addition to building geometry, this software can be used to perform computational simulations of fluid dynamics with an integrated flow simulation feature. The objectives of this research are as follows: (1) To determine the effect of variations in the opening angle on the coefficient of lift $\mathrm{C}_{\mathrm{L}}$ and block $\mathrm{C}_{\mathrm{D}} \mathrm{Archimedes}$ wind turbine design., (2) To provide new knowledge of types of Archimedes wind turbines.

\section{Literature Review}

Conducted a study on a Comparative Study between the Archimedes Spiral Turbine and the Propeller Turbine with Wind Angle Effects. He modified the type of wind turbine on a small scale and made it using Fused Deposition Modeling, with Nylon material FDM [2] [4]. The purpose of making the prototype is to investigate its performance. Judging from the effect of the opening angle of the wind, it can be seen that the lifting force affects to rotate the generator in order to produce electrical energy obtained from the Archimedes spiral wind turbine (ASWT). The rotor in the ASWT increases the output power, the power coefficient $\left(\mathrm{C}_{\mathrm{D}}\right)$ and electricity generation when the incoming flow wind speed increases from 6.0 to $10 \mathrm{~m} / \mathrm{s}$. [5] made an observation about the Spiral Logarithm, commonly known as the Archimedes screw design or the equiangular. In particular, logarithmic spirals can be observed in nature (such as nautilus, cowie, forest snail, weed) [6]. 
Conducted a study on the Design, Fabrication and Analysis of the Fibonacci Horizontal Spiral Wind Turbine. This research focuses on the field of wind energy which continues to grow. The goal is to design, build a wind turbine with the help of Fibonacci spirals [1]. The blade profile is helicalcone. An attempt has been made to use such turbines in urban areas while reducing the installation height. The 3D blade model is designed on solid objects to study static simulations. Studies show that the turbine can generate Rpm at a low wind speed of $5 \mathrm{~m} / \mathrm{s}$. The results showed that the modified spiral wind turbine is ideal for urban locations due to its ability to withstand wind turbulence. The results show that the minimum speed required to run the turbine is $5 \mathrm{~m} / \mathrm{s}$. And the maximum efficiency obtained is 71 , $38 \%$. The turbine shows an increase in varying wind speeds. The minimum wind speed required to rotate the blade is $5 \mathrm{~m} / \mathrm{s}$ for optimal wind turbine performance [7].

\subsection{Fibonacci Sequence}

The Fibonacci sequence is a sequence where each term is the sum of the previous 2 digits [8]. These Fibonacci numbers are generated on the basis of starting with the number 0 added to 1 , which can result in the number 1 . The result of the 1 being added to the previous number is 1 , resulting in the number 2. Following this logic, each new Fibonacci number comes from adding a number. the current number to the previous number. As for, to further demonstrate this process, the first ten Fibonacci numbers are illustrated (in table 3.1). The third row of column 1 illustrates the simple calculations required to obtain the Fibonacci numbers. While the term "Fibonacci Sequence" may sound eccentric, its calculations are easy to understand for anyone with only simple additional skills [9] [10].

Table 1. First Fibonacci Numbers and Derivations

\begin{tabular}{ccccccccccc}
\hline F0 & F1 & F2 & F3 & F4 & F5 & F6 & F7 & F8 & F9 & F10 \\
\hline 0 & 1 & 1 & 2 & 3 & 5 & 8 & 13 & 21 & 34 \\
\hline & & & & & & & & & & \\
\hline
\end{tabular}

When a series of squares is made with the length according to the first Fibonacci numbers $1 \times 1,2 \times 2,3 \times 3,5 \times 5,8 \times 8$ [9]. Then arranged according to the Fibonacci sequence to create a special spiral pattern. Look at the box image below, drawn based on the Fibonacci sequence [11] [12].

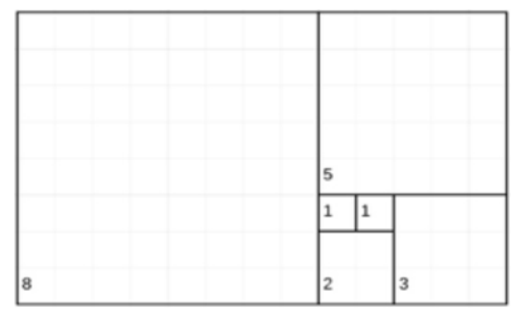

Fig 1. Fibonacci Sequence

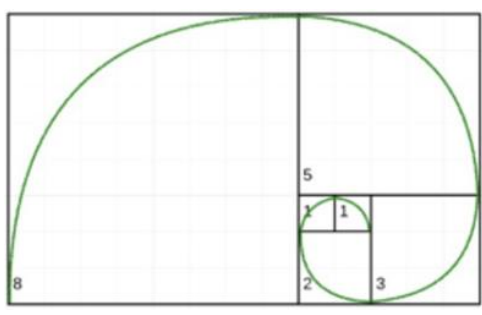

Fig 2. Spiral Curve

Then draw a curve in each square, making a spiral shape and is generally called a Fibonacci spiral. The spiral can be expanded by adding more squares based on the Fibonacci sequence (Figure 2).This pattern can be found in general in nature such as nautilus, cowie, forest snails, weeds with a logarithmic spiral. The spider webs show a similar pattern. The low pressure region over Iceland and the vortex galaxy above the water resembles a logarithmic spiral Figure 3 is the logarithmic spiral shape of nature [5] [13].

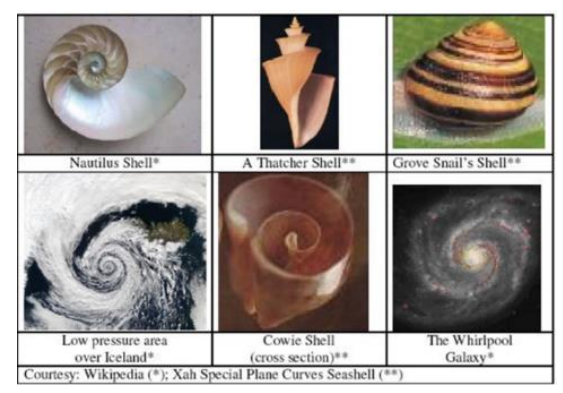


Fig 3. Spiral Logarithmic [5]

\subsection{Archimedes Wind Turbine}

Archimedes wind turbine or Archimedes spiral wind turbine (ASWT) is a type of small-scale horizontal axis wind turbine designed on the Archimedean spiral principle. The turbine harvests energy from the wind by directing its flow $90^{\circ}$ relative to its original direction. Unlike horizontal wind turbines that use, ASWT uses lift and drag [14] [15].
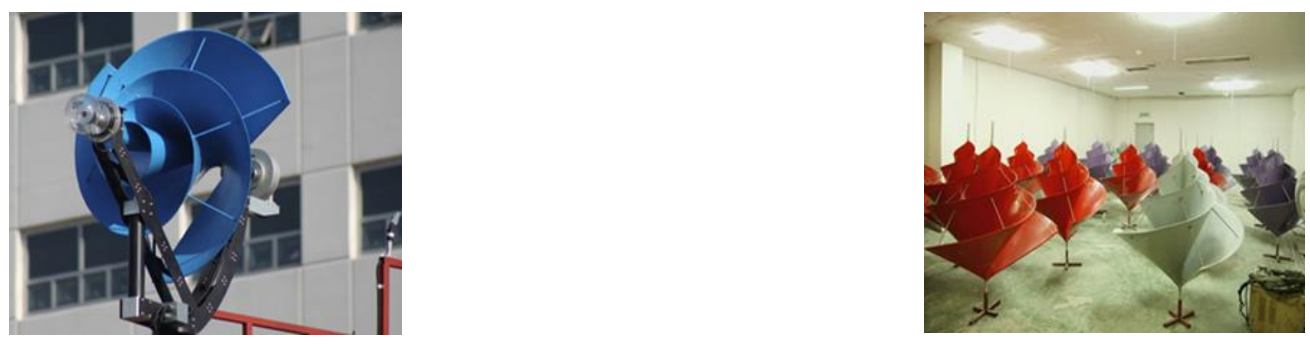

Fig 4. Archimedes Wind Turbine [16]

\subsection{Spiral Archimedes}

Archimedes spiral is a transcendent curve that occurs when a point, starting at the origin, visits the origin uniformly and uniformly moves away from it, the distance of the point from the origin of the Archimedes coil is proportional to the associated pitch angle, the design is inspired by the Fibonacci spiral design or better known as the golden ratio [16].

\subsection{Spiral Blades Design (Fibonacci Spiral)}

In 3rd century BC Greece, the mathematician Archimedes applied spiral curves (Fibonacci Spiral) to create blade designs with approximate spirals (Fibonacci spirals) created by drawing circular arcs connecting opposite square corners on tiles or Fibonacci sequences. in Figure 2.2 using squares with sizes $1,1,2,3,5$ and 8 [1].

\subsection{Pitch of the blade}

The pitch of the blades is the axial distance measured when the spiral rotates one complete revolution. Correct estimation is an important factor to produce maximum power coefficient. Pitch is varied and learned in the simulation process [14].

\subsection{Aperture Angle}

The aperture angle, denoted of the turbine is generally used to define the angle, at which air exits the turbine with respect to the incoming air. Meanwhile, the difference that is created along the turbine blades is influenced by the opening angle. In general, the opening angle is varied and studied in the simulation process [14].

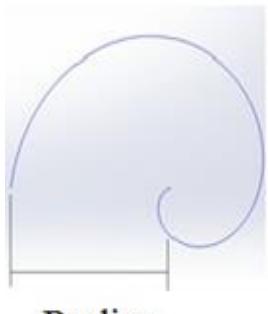

Radius

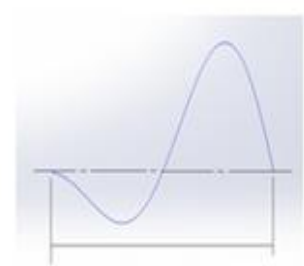

Pitch

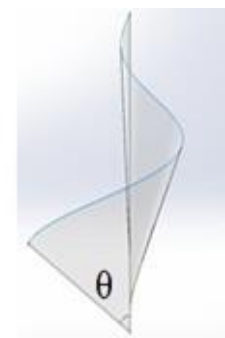

Fig 5. Blade Parameters

\subsection{Radius}

Radius is the maximum distance of the turbine angle from the center of the shaft. It is this that determines the sweep area of the turbine during rotation which determines the amount of air interacting with the turbine. To provide the same input power, a constant radius of 75 mm is considered for all geometries [14]. 


\subsection{Lift Coffient and Drag in Archimedes Angin Wind Turbines}

The Archimedes wind turbine blades are of resistance type (drag) and with respect to the tip of the blade they are conical or spiral which is characteristic of the lift type. Archimedes Wind turbine blades have the characteristics of both[1]. In general, the turbine has coefficient and drag characteristics which are described as follows:

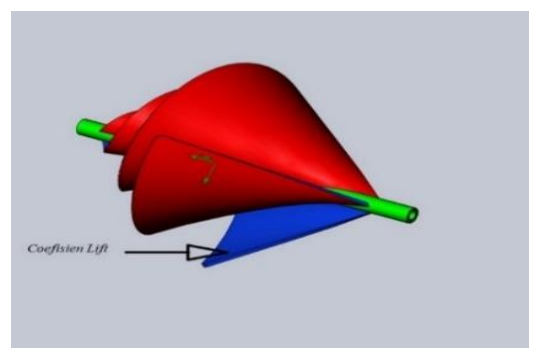

Fig 6. Lift Coefficient of Archimedes Wind Turbine

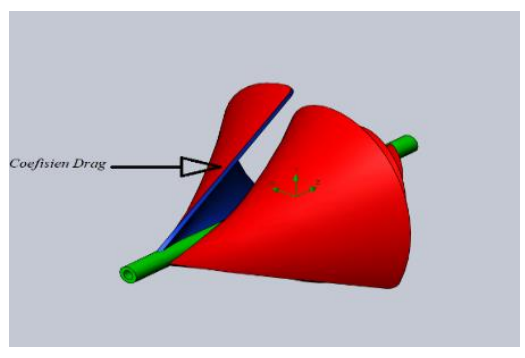

Fig 7. Drag Coefficient on Archimedes Wind Turbine

Based on Figures 6 and 7, it can be understood that the lift coefficient and drag will work on the Archimedes wind turbine blade according to the color indicated by the arrow between: blue for lift coefficient and red drag coefficient. These forces will act on the Archimedes wind turbine blades and rotate them clockwise. The turbine blade design has a flat surface that extends to provide depth and the shape is considered to have volume.

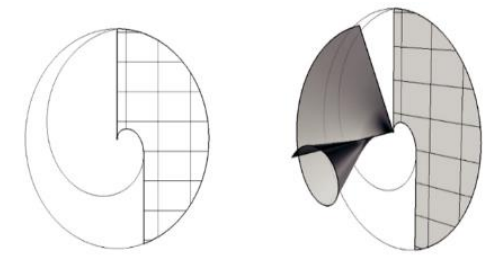

Fig 8. The semi-circle is rotated to get a Spiral shape

The shape that has the volume makes the turbine design have $C_{L}$ and $C_{D}$. The natural phenomena that are often encountered include insects (bees) and bats that can produce lift and drag with flat membrane wings [1]. Brow University conducted research, showing bats have evolved. Especially on the wings are able to store energy, when flying from one place to another. According to biologists, physicists and engineers at Brow University, Providence, United States. Analyze the dynamics of bat wing movement, When flying in detail. Scientists can tell that it can fold their wings into their bodies. The folding movement, which scientists believe is a pause or rest, is said to be able to save $65 \%$ of energy, then the stored energy is used for the next flap so that the bat can fly longer and higher [17].This can happen, because bats have thin wings called patagium, formed by the finger bones (digiti) experiencing the elongation of the second to fifth fingers so that it functions as a wing framework, and consists of many blood vessels. The connective tissue fibers and nerves are the real difference between the wings of a bat wing and a bird's wing is in the extension of their fleshy body and their featherless wings [18].

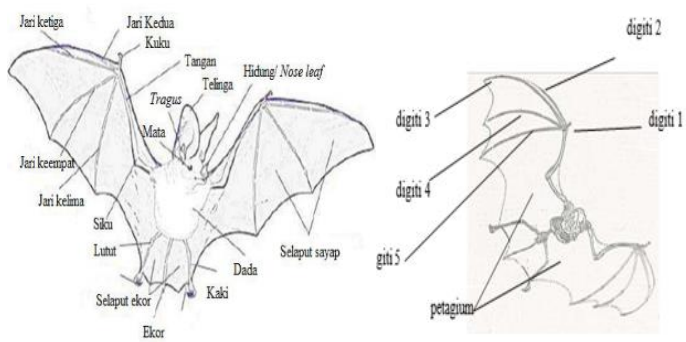

Fig 9. Bat Wing Structure 
Bats use the same aerodynamic mechanisms as insects (bees) and rely on horizontal air vortices of drag called LEV (leading edge vortex) to keep their bodies afloat.

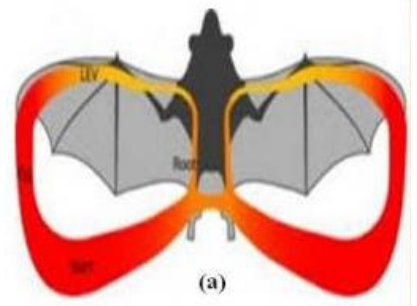

Fig 10. (a) LEV in Bats

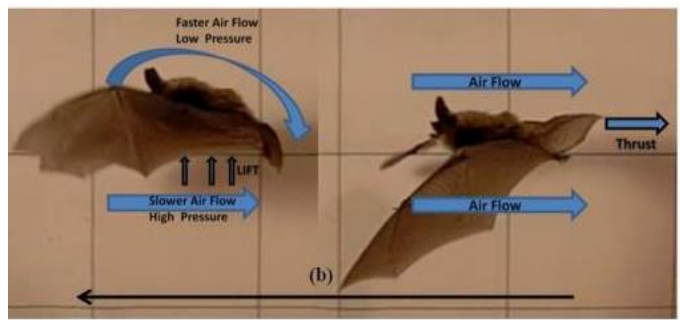

Fig 10. (b) Bat Wing Flapping and Hovering Motion

LEV is formed when a bat flaps its wings downwards (downstroke). This creates a strong enough upward thrust so the bat doesn't fall down during slow motion or hovering. The thrust generated by the LEV contributes $40 \%$ of the force required to float [19]. For insects (bees) use the same thing, but the movement of the wings is different. Insects (bees) flap their wings back and forth. When bees flap their wings forward, they will first rotate them almost 90 degrees before pulling them back again. This movement produces a vortex (rotating airflow) at the top of the bee's wings, making the air pressure in that section lower than the air pressure around it, so that the body is lifted upwards. For more details, it can be seen in the 3D simulation image below which shows the vortex (red color that appears due to the movement of the bee's wings).

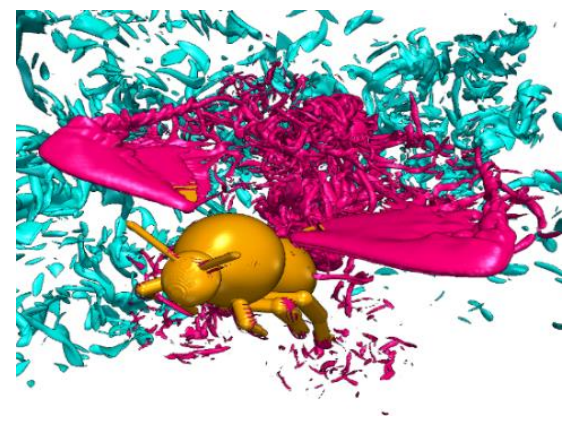

Fig 11. Simulation of Air Vortex When Bees Fly

Uniquely, this way of flying is very efficient. When the bee is in a fairly strong wind, the bee does not need more energy to maintain its flight condition, because the drag that passes through the wings is utilized as well as the bat. A study conducted by R. Dudley and CP Ellington from the University of Cambridge showed that the power they need to fly is not affected by the speed of the surrounding air [20].

\section{Method}

In this study, the author carried out several stages, namely the author made a lot of efforts to find references from various sources including google and youtube, with the desire to get a more interesting theme than previous research. Then, obtained the theme of the Archimedes wind turbine which is unique in terms of design than the previous wind turbine design. Seeing this potential, the author raised the theme of Archimedes wind turbine design with the aim of introducing readers to the uniqueness of the design and the author hopes that later it can be applied in Indonesia. Furthermore, making Archimedes blade design geometry by varying the opening angle $35^{\circ}, 45^{\circ}, 65^{\circ}$ in Solidworks 2018 and inputting data in the form of wind speeds of $5.5 \mathrm{~m} / \mathrm{s}$ and $15 \mathrm{~m} / \mathrm{s}$, pressure distribution of $1 \mathrm{~atm}$.

\subsection{Design Archimedes Wind Turbin}

Archimedes wind turbine design is shown in the image below : 


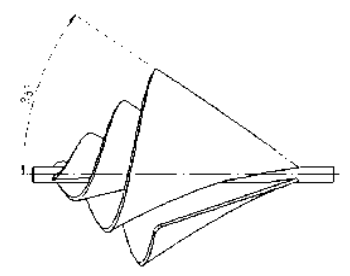

Fig 12. Opening Angle of $35^{\circ}$

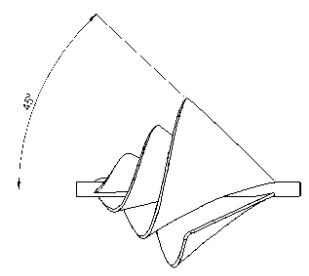

Fig 13. Opening Angle of $45^{\circ}$

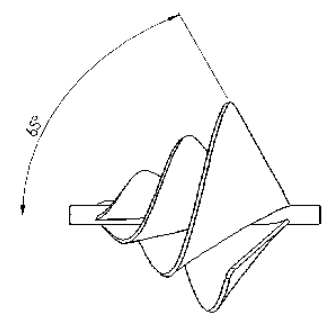

Fig 14. Opening Angle of $65^{\circ}$

\section{Results and Discussion}

The results of the study on the Lift Coefficient $\left(\mathrm{C}_{\mathrm{L}}\right)$ and drag $\left(\mathrm{C}_{\mathrm{D}}\right)$ on the Archimedes wind turbine with a pressure distribution of 1 atm using wind speeds of $5,5 \mathrm{~m} / \mathrm{s}$ and $15 \mathrm{~m} / \mathrm{s}$ with a turbulent flow type Re 1200 . With variations in the opening angle $35^{\circ}, 45^{\circ}, 65^{\circ}$ it can be seen in table 2 .

Table 2. Data from Flow Simulation Solidwork 2016

\begin{tabular}{cccccc}
\hline & Opening & $\begin{array}{c}\text { Coefficient of } \\
\text { Lift }\left(\mathrm{C}_{\mathrm{L}}\right)\end{array}$ & $\begin{array}{c}\text { Coefficient of } \\
\text { Drag }\left(\mathrm{C}_{\mathrm{D}}\right)\end{array}$ & $\begin{array}{c}\text { Coefficient of } \\
\text { Lift }\left(\mathrm{C}_{\mathrm{L}}\right)\end{array}$ & $\begin{array}{c}\text { Coefficient of } \\
\text { Drag }\left(\mathrm{C}_{\mathrm{D}}\right)\end{array}$ \\
\cline { 3 - 6 } & \multicolumn{2}{c}{$\begin{array}{c}\text { Wingle Speed of } \\
5,5 \mathrm{~m} / \mathrm{s}\end{array}$} & \multicolumn{2}{c}{$\begin{array}{c}\text { Wind Speed of } \\
15 \mathrm{~m} / \mathrm{s}\end{array}$} \\
\hline 1. & $35^{\circ}$ & $1.07 \mathrm{E}+02$ & $4.02 \mathrm{E}+04$ & $2.20 \mathrm{E}+03$ & $9.76 \mathrm{E}+02$ \\
\hline 2. & $45^{\circ}$ & $1.08 \mathrm{E}+04$ & $1.77 \mathrm{E}+01$ & $5.51 \mathrm{E}+04$ & $4.12 \mathrm{E}+02$ \\
\hline 3. & $65^{\circ}$ & $1.84 \mathrm{E}+06$ & $3.68 \mathrm{E}+04$ & $5.96 \mathrm{E}+01$ & $1.33 \mathrm{E}+03$ \\
\hline
\end{tabular}

In table 2 above, it can be obtained a graph of the Lift Coefficient $\left(\mathrm{C}_{\mathrm{L}}\right)$ as follows:

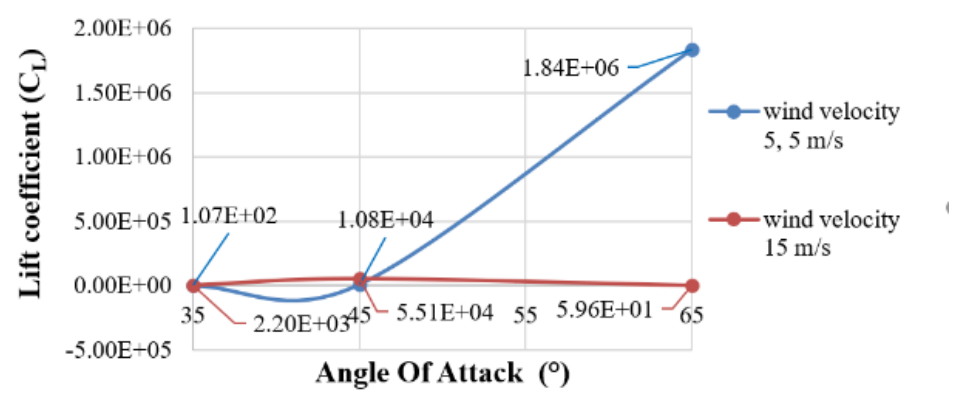

Fig 12. Lift Coefficient Comparison Graph $\left(\mathrm{C}_{\mathrm{L}}\right)$ Wind Speed $5,5 \mathrm{~m} / \mathrm{s}$ and $15 \mathrm{~m} / \mathrm{s}$ 
From the graphic data of the test results of the lift coefficient $\left(\mathrm{C}_{\mathrm{L}}\right)$ above it can be seen that at the opening angle of $35^{\circ}, 65^{\circ}$ there is a significant increase, when the wind speed is $5,5 \mathrm{~m} / \mathrm{s}$ and $15 \mathrm{~m} / \mathrm{s}$. In the graph it can be seen that with the same wind speed, the value of $\mathrm{C}_{\mathrm{L}}$ is steady and increase at wind speed of $5.5 \mathrm{~m} / \mathrm{s}$ and $1.07 \mathrm{E}+02$ at an opening angle of $35^{\circ}$. While at the opening angle of $65^{\circ}$ the result was $1.84 \mathrm{E}+026$. Then at a wind speed of $15 \mathrm{~m} / \mathrm{s}$ with an opening angle of $35^{\circ}, 45^{\circ}, 65^{\circ}$ get an increase in value $\left(\mathrm{C}_{\mathrm{D}}\right)$ stably at $2.20 \mathrm{E}+02$ at an opening angle of $35^{\circ}$ and $5.96 \mathrm{E}+01$ at an opening angle of $65^{\circ}$.

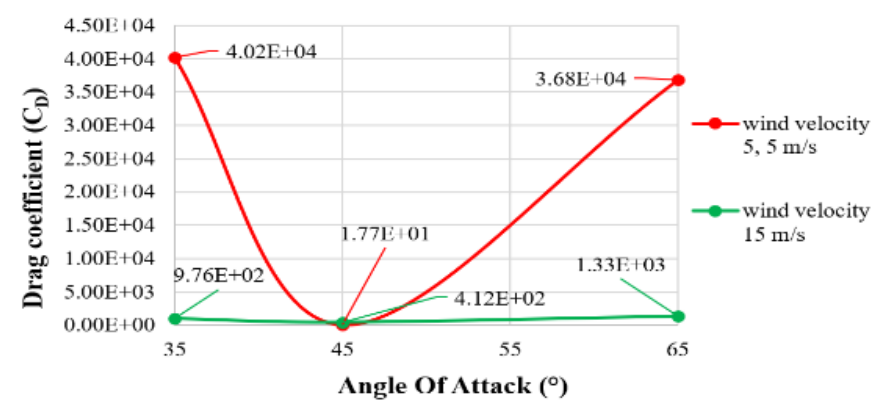

Fig 13. Graph of Comparison the Drag Coefficient $\left(C_{D}\right)$ at Wind Speed of $5,5 \mathrm{M} / \mathrm{S}$ And $15 \mathrm{M} / \mathrm{s}$

In the graph above it can be seen and understood that the drag coefficient $\left(\mathrm{C}_{\mathrm{D}}\right)$ with an opening angle of $35^{\circ}$ wind speed $15 \mathrm{~m} / \mathrm{s}$ there was a decrease from $9.76 \mathrm{E}+02$ to $1.33 \mathrm{E}+03$ at an opening angle of $65^{\circ}$. As for the wind speed of $5.5 \mathrm{~m} / \mathrm{s}$ with an opening angle of $35^{\circ}$ get the coefficient of drag $\left(C_{D}\right)$ which was initially 4.02 E+04 decreased significantly by 1.77 E+01 at an opening angle of $45^{\circ}$ with similar wind speeds opening angle of $65^{\circ}$ with a wind speed of $5.5 \mathrm{~m} / \mathrm{s}$, the result is $3.68 \mathrm{E}+04$.

\subsection{Discussion}

Judging from the data obtained, the value of the force coefficient $\left(\mathrm{C}_{\mathrm{L}}\right)$ work on the Archimedes wind turbine. It is assumed that the design of the Archimedes wind turbine which seems eccentric, spiral-shaped causes the fluid flow to flow on the inner surface of the turbine blade. At an opening angle of $35^{\circ}, 65^{\circ}$ a speed of $15 \mathrm{~m} / \mathrm{s}$ which produces a value of $\mathrm{C}_{\mathrm{L}}$ and $\mathrm{C}_{\mathrm{D}}$ larger than the opening angle of $35^{\circ}, 45^{\circ}, 65^{\circ}$ with different wind speeds of $5.5 \mathrm{~m} / \mathrm{s}$.

Because the opening angle receives the most sweep or captures the air. This is the case with the airfoil theory which is generally recognized by most scientists. That on the airfoil, the larger the opening angle or the opening angle will be $\mathrm{C}_{\mathrm{L}}$ This happens because as the opening angle increases, the stagnation position shifts from the initial tip to the bottom of the airfoil, this causes the air pressure to increase at the surface of the airfoil [21].

In general, the value of the drag coefficient $\left(C_{D}\right)$ acts on any passing airborne particles, and such is usually a disadvantage found in land transport vehicle designs (cars and motorcycles) or in the air (planes and helicopters). These transport vehicle designs, designed by engineers to minimize losses the $C_{D}$. However, in the Archimedes wind turbine, $C_{D}$ the obtained periodically can be used to turn the Archimedes turbine through the spiral blade path, and convert the kinetic energy of the wind into mechanical which is transmitted to generators and lighting or electricity in urban areas and even in remote villages. [2].

\section{Conclusion}

From the simulation results, the flow wind speed coefficient of lift $\left(\mathrm{C}_{\mathrm{L}}\right)$, drag coefficient $\left(\mathrm{C}_{\mathrm{D}}\right)$ Archimedes wind turbines with variations in opening angles of $35^{\circ}, 45^{\circ}, 65^{\circ}$ using wind speeds of $5.5 \mathrm{~m} / \mathrm{s}$ and $15 \mathrm{~m} / \mathrm{s}$. The value of $\mathrm{C}_{\mathrm{L}}$ at an opening angle of $35^{\circ} 1,07 \mathrm{E}+02$ with a wind speed of $5,5 \mathrm{~m} / \mathrm{s}$ and a wind speed of $15 \mathrm{~m} / \mathrm{s}$ gets a value $\mathrm{C}_{\mathrm{L}}$ of $2.20 \mathrm{E}+03$. The opening angle of $45^{\circ}$ and $65^{\circ}$ with a similar wind speed, an increase in the value of $C_{L}$. The value of the drag coefficient $\left(C_{D}\right)$ Archimedes wind turbine with a variation of the opening angle of $35^{\circ}$, the results obtained are $4.02 \mathrm{E}+04$ at a wind speed of $5.5 \mathrm{~m} / \mathrm{s}$ and $9.76 \mathrm{E}+02$ at a wind speed of $15 \mathrm{~m} / \mathrm{s}$. Meanwhile, at the value of $\mathrm{C}_{\mathrm{D}}$ opening angle of $45^{\circ}$ is $1.77 \mathrm{E}+01$ at a wind speed of $5.5 \mathrm{~m} / \mathrm{s}$ and at a speed of $15 \mathrm{~m} / \mathrm{s}$ there is an increase of $5.51 \mathrm{E}+04$. Opening angle of $65^{\circ}$ wind speed 5,5 $\mathrm{m} / \mathrm{s}$ value $\mathrm{C}_{\mathrm{D}}$ of $3.68 \mathrm{E}+04$ and a wind speed of $15 \mathrm{~m} / \mathrm{s}$ value $\left(\mathrm{C}_{\mathrm{D}}\right)$ decreased by $1.33 \mathrm{E}+03$.

\section{Reference}

[1] Y. Patil, "Design, Fabrication And Analysis Of Fibonacci Spiral Horizontal Axis Wind Turbine," Int. J. Aerosp. Mech. Eng., vol. 5, no. 2, pp. 19-22, 2018.

[2] A. T. Mustafa and H. A. Jaleel, "A comparison study between Archimedes spiral turbine and propeller turbine with wind attack angle effect," AIP Conf. Proc., vol. 2213, no. March, 2020, doi: 10.1063/5.0000144. 
[3] B. Munson, "Mekanika Fluida," Erlangga, no. Jakarta, pp. 1-50, 2002.

[4] N. Sylvia, Y. Yunardi, H. Husni, and A. Muslim, "Simulation of CO2 Gas Adsorption Process Flow at Cyclone Gas Outlet in Palm Oil Mills Using Computation Fluid Dynamic Simulation," Int. J. Eng. Sci. Inf. Technol., vol. 1, no. 3, 2021, doi: 10.52088/ijesty.v1i3.112.

[5] S. K. Mishra, "Fitting a Logarithmic Spiral to Empirical Data With Displaced Origin," SSRN Electron. J., no. November, 2011, doi: 10.2139/ssrn.897863.

[6] R. Rinaldy and M. Ikhsan, "Determinant Analysis Of Conflict On Project Results In Aceh Province," Int. J. Eng. Sci. Inf. Technol., vol. 1, no. 1, 2021, doi: 10.52088/ijesty.v1i1.37.

[7] Y. Yurike, Y. Yonariza, and R. Febriamansyah, "Patterns of Forest Encroachment Behavior Based on Characteristics of Immigrants and Local Communities,” Int. J. Eng. Sci. Inf. Technol., vol. 1, no. 4, 2021, doi: 10.52088/ijesty.v1i4.175.

[8] S. Sinha, "The Fibonacci Numbers and Its Amazing Applications," Int. J. Eng. Sci. Invent., vol. 6, no. 9, pp. 7-14, 2017.

[9] A. R. Watson, "The Golden Relationships: An Exploration of Fibonacci Numbers and Phi," pp. 5-61, 2017.

[10] T. Imankulov, B. Daribayev, and S. Mukhambetzhanov, "Comparative analysis of parallel algorithms for solving oil recovery problem using cuda and opencl," Int. J. Nonlinear Anal. Appl., vol. 12, no. 1, 2021, doi: 10.22075/IJNAA.2021.4809.

[11] N. Minarova, "The Fibonacci Sequence: Nature's Little Secret," Cris - Bull. Cent. Res. Interdiscip. Study, vol. 2014, no. 1, pp. 7-17, 2014, doi: 10.2478/cris-2014-0001.

[12] R. H. Buti and A. K. Sachit, "On subclass of analytic univalent functions defined by fractional differ-integral operator i," Int. J. Nonlinear Anal. Appl., vol. 12, no. Special Issue, 2021, doi: 10.22075/IJNAA.2021.4844.

[13] D. Abdullah et al., "Expert System Diagnosing Disease of Honey Guava Using Bayes Method," in Journal of Physics: Conference Series, 2019, doi: 10.1088/1742-6596/1361/1/012054.

[14] U. Nepal, S. Sapkota, A. Bhattarai, and H. Prasad Bashyal, "Design, CFD Analysis and Modelling of Archimedean-Spiral type Wind Turbine," pp. 1-9, 2019.

[15] D. Kumar, "Power System Restoration Using Multilayer Perceptron," Int. J. Eng. Sci. Inf. Technol., vol. 1, no. 1, 2021, doi: 10.52088/ijesty.v1i1.35.

[16] M. Burazer, "UNIVERSITY OF SPLIT FACULTY OF ELECTRICAL ENGINEERING , MECHANICAL ENGINEERING AND NAVAL ARCHITECTURE GEOMETRIC MODELLING OF Miroslav Burazer-Turko Archimedes spiral wind turbine,” no. December, pp. 2-4, 2015.

[17] L. Ahmad, "Gerak-Sayap-Kelelawar-Bisa-Simpan-Energi-untuk-Terbang-Okezone-techno.” 2012.

[18] G. A. Feldhamer, L. C. Drickamer, S. H. Vessey, J. F. Merritt, and C. Krajewski, Adaptation, Diversity, Ecology Fourth Edition. 2015.

[19] Vandha, "Menguak-Rahasia-Kelelawar-Selamat-Datang-di-Blog-Pandapotan-Harahap." 2013.

[20] H. Zarkasy, "Mission-not-Impossible-Cara-Lebah-Terbang-yang-Memukau." 2021.

[21] S. Nurcahyadi, “AIRFOIL SIMETRIS TERHADAP KOEFISIEN ANGKAT,” vol. 11, no. 1, pp. 110-124, 2008. 